\title{
Vivências Acadêmicas e Empregabilidade de Universitários em Final de Curso
}

\author{
Karen Cristina Alves Lamas ${ }^{1}$ \\ Rodolfo A. M. Ambiel \\ Brenda Taís A. O. de Lócio e Silva \\ Universidade São Francisco, Itatiba, São Paulo, Brasil
}

\begin{abstract}
Resumo
O objetivo deste estudo foi explorar as associações entre vivências acadêmicas e empregabilidade em universitários do último ano de graduação e analisar se há diferenças nessas variáveis entre os cursos participantes, Psicologia e Administração. Participaram 60 estudantes do último ano de graduação de uma universidade particular do interior paulista, sendo $76,6 \%$ do sexo feminino, com média de idade de 26,7 anos $(D P=5,0)$. Para a coleta de dados foram utilizados o Questionário de Vivências Acadêmicas Reduzido (QVA-r) e a Escala de Empregabilidade. Os resultados mostraram que não houve diferença significativa entre os cursos em nenhuma das variáveis. Quanto à associação entre vivências acadêmicas e empregabilidade, todos os fatores do QVA-r apresentaram correlações significativas com alguma dimensão da Escala de Empregabilidade, destacando-se a dimensão Interpessoal que se associou a todas as dimensões de empregabilidade. Considera-se que a integração acadêmica do estudante está associada à capacidade de tornar-se empregável. Portanto, tanto os estudantes quanto os gestores devem ficar atentos às oportunidades que podem contribuir para desenvolvimento das competências de empregabilidade, sem se restringirem à grade curricular tradicional.
\end{abstract}

Palavras-chave: Empregabilidade, estudantes universitários, desenvolvimento profissional, adaptação acadêmica, transição escola-trabalho.

\section{Academic Experiences and Employability of Senior College Students}

\begin{abstract}
The aim of this study was to explore the associations between academic experiences and employability in senior college students and verifiy if there is any difference in these variabels between Psychology and Business Manageament students. The participants were 60 students in their final year of undergraduate courses from a private university in São Paulo, Brazil, being $76.6 \%$ female, with a mean age of 26.7 years $(S D=5.0)$. For data collection we used Questionário de Vivências Acadêmicas Reduzido (QVA-r) and Escala de Empregabilidade. The results have shown no significant difference between the courses in any of the variables. Regarding the association between academic experiences and employability, all factors QVA-r showed significant correlations with some dimension of Escala de Empregabilidade, highlighting the interpersonal dimension which partnered with all dimensions of employability. It is considered that the academic integration of the student is associated with the abil-
\end{abstract}

1 Endereço para correspondência: Programa de Pós-Graduação Stricto Sensu em Psicologia, Universidade São Francisco, Rua Alexandre Rodrigues Barbosa, 45, Centro, Itatiba, SP, Brasil 13251-900. E-mail: karen_lammas@yahoo.com.br,rodolfo.ambiel@usf.edu.bre brelocio@gmail.com 
ity to become employable. Therefore, both the students and managers should be alert to opportunities that may contribute to the development of employability skills, without if they restrict to the traditional curriculum.

Keywords: Employability, college students, professional development, academic adjustment, schoolto-work transition.

\section{Vivencias Académicas y Empleabilidad de Universitarios del Final del Curso}

\section{Resumen}

El objetivo del estudio fue investigar las asociaciones entre vivencias académicas y empleabilidad en universitarios del último año de grado, y analizar si hay diferencias en esas variables en función de los cursos -psicología y administración de empresas- escogidos por los participantes. Participaron 60 estudiantes del último año de grado de una universidad privada del interior paulista, siendo $76,6 \%$ mujeres, con una media de 26,7 años $(S D=5.0)$. Para la recolección de datos fueron utilizados el Questionário de Vivências Acadêmicas Reduzido (QVA-r) y la Escala de Empregabilidade. Los resultados mostraron que no hubo diferencia significativa entre los cursos, en ninguna de las variables estudiadas. Sobre la asociación entre vivencias académicas y empleabilidad, todos los factores del QVA-r presentaron correlaciones significativas con alguna dimensión de la Escala de Empregabilidade, destacándose la dimensión Interpersonal, que se asoció a todas las dimensiones de empleabilidad. Se considera que la integración académica del estudiante está asociada a la capacidad de tornarse empleados. Por lo tanto, los estudiantes y los administradores deben estar atentos a las oportunidades que pueden contribuir para el desarrollo de las competencias de empleabilidad, sin restringirse al curriculum tradicional.

Palabras clave: Empleabilidad, estudiantes universitarios, desarrollo professional, ajuste académico, transición entre la escuela y el trabajo.

Os cursos de graduação têm um caráter de formação técnica e científica, com objetivo de preparação para o mercado de trabalho e, ao seu final, os universitários se deparam com a necessidade de buscar oportunidades e se efetivarem em uma ocupação. De acordo com Rosenberg, Heimler e Morote (2012) tal empreitada tende a ser realizada com mais sucesso à medida que vivências ocorridas durante o curso facilitem o desenvolvimento de outras habilidades, além das técnicas.

O Ensino Superior traz para o estudante diferentes tarefas e contextos, aos quais ele precisa se adaptar para que ao longo do curso alcance determinado nível de rendimento acadêmico e satisfação com os resultados. Tais vivências acadêmicas, de acordo com Almeida, Soares e Ferreira (2000) podem ser categorizadas em quatro dimensões da adaptação ao contexto universitário, a saber, acadêmico, pessoal, social e voca- cional. $\mathrm{O}$ domínio acadêmico se refere à adaptação ao ritmo de trabalho e ao desenvolvimento de estratégias de aprendizagem para responder aos novos sistemas de ensino e avaliação. A dimensão social diz respeito a padrões mais maduros de relacionamento interpessoal com familiares, docentes, colegas, pessoas do sexo oposto e figuras de autoridade. O domínio pessoal está associado ao desenvolvimento de forte senso de identidade, autoestima, autoconhecimento e uma visão pessoal do mundo. Por fim, a dimensão vocacional compreende o desenvolvimento de uma identidade vocacional, que envolve tomada de decisão, exploração e compromisso com um projeto de carreira.

Para avaliar tais dimensões, Almeida, Soares e Ferreira (2002) construíram uma versão reduzida do Questionário de Vivências Acadêmicas (QVA-r) proposto por Almeida e Ferreira em 1997, traduzindo os quatro domínios em 
quatro subescalas, quais sejam, Estudos, Pessoal, Interpessoal e Carreira. Os autores acrescentaram a dimensão denominada Institucional, que caracteriza a adaptação à estrutura e funcionamento da instituição de ensino. Ainda neste texto, destacaram na dimensão social/interpessoal a presença de itens relacionados ao envolvimento do estudante em atividades extracurriculares. Quanto mais elevado o escore, maior o nível de adaptação do estudante ao contexto acadêmico na respectiva área.

Algumas pesquisas investigaram as vivências acadêmicas de estudantes universitários utilizando as versões do QVA, além de explorar associações com outras variáveis, tais como curso frequentado, semestre do curso, relações familiares e interesses profissionais (Igue, Bariani, \& Milanesi, 2008; Lemos, 2010; Noronha, Martins, Gurgel, \& Ambiel, 2009; Schleich, 2006; Soares, Baldez, \& Mello, 2011; Teixeira, Castro, \& Piccolo, 2007). Para ilustrar como o nível de adaptação acadêmica se apresenta em relação aos cursos e momento da formação, são descritos alguns estudos.

Igue et al. (2008) verificaram, em sua pesquisa com acadêmicos de Psicologia que cursavam o $1^{\circ}$ e o $5^{\circ}$ e ano do curso, que os estudantes apresentaram escores acima da média em todas as dimensões, com maior elevação na dimensão Carreira, relacionada ao domínio vocacional. Na comparação entre os períodos cursados, os alunos iniciantes apresentaram média mais elevada na dimensão Institucional, enquanto os alunos concluintes se destacaram na dimensão Estudos.

Pesquisa semelhante foi realizada por Noronha et al. (2009), na qual foi analisada a adaptação acadêmica entre estudantes dos anos iniciais e finais dos cursos de Direito e Administração. Os resultados mostraram que os estudantes de Direito obtiveram maiores médias nas dimensões Interpessoal e Carreira, enquanto os estudantes de Administração destacaram-se em Institucional. Quanto ao semestre do curso, os alunos iniciantes de graduação em Administração tiveram médias mais elevadas que os finalistas nas dimensões Carreira, Estudo e Institucional, enquanto os alunos iniciantes de Direito também se sobressaíram na dimensão Institucional e os concluintes na dimensão Interpessoal.

No estudo de Teixeira et al. (2007), o objetivo foi investigar a adaptação acadêmica de 342 estudantes distribuídos entre vários cursos. De acordo com os resultados, os estudantes apresentaram níveis de adaptação satisfatórios, acima do ponto médio da escala. A dimensão Carreira com a média mais alta se correlacionou negativamente com a variável ano do curso, indicando que com o passar do tempo, o envolvimento com a carreira tende a diminuir, o que não era esperado, uma vez que a expectativa é de que ocorra um aumento da identificação com a profissão ao longo da graduação. Uma hipótese dos autores para esse achado é de que os alunos em períodos mais avançados do curso tenham ajustado suas expectativas em relação à profissão diante do maior conhecimento sobre limitações e frustrações da carreira.

Ao final do curso de graduação, quando há a saída da universidade e a inserção no mercado de trabalho, existe a necessidade de adaptação, autonomia, responsabilidade e demonstração das habilidades e conhecimentos. Com a transição da vida acadêmica à atividade profissional, colocam-se em prova, então, todas as vivências do estudante adquiridas na universidade para conseguir um emprego. Será neste processo que o universitário deverá usar suas habilidades e competências adquiridas durante a graduação para tornar-se empregável (Rosenberg et al., 2012; Schleich, 2006).

Segundo Clarke e Patrickson (2008) não há uma definição específica para empregabilidade. Após pesquisar várias visões de autores sobre empregabilidade, Campos (2011) resume o conceito como o "preparo do indivíduo para conseguir um emprego ou trabalho e em seguida mostrar-se competente para mantê-lo ou ingressar em outro" (p. 46). De acordo com a autora, empregabilidade seria a preparação para a busca do trabalho, sem deixar de lado as características pessoais do indivíduo que exerceriam influência na eficácia de busca de empregos. É essa a perspectiva de empregabilidade adotada neste trabalho.

Quanto às habilidades que caracterizam a empregabilidade, pesquisadores afirmam que se 
tratam de competências gerais, não específicas a determinada ocupação ou emprego (Campos, 2010; Clarke \& Patrickson, 2008). Guzman e Choi (2013) consideraram em seu estudo três competências, quais sejam, comunicação, resolução de problemas e trabalho em equipe. Rosenberg et al. (2012) deram mais ênfase em habilidades que o mercado costuma exigir dos trabalhadores, sendo elas, habilidades matemáticas e linguísticas, pensamento crítico, liderança, gestão, habilidades interpessoais, tecnologia da informação, pensamento sistêmico e ética no trabalho. Campos (2011) ao propor a Escala de Empregabilidade, utilizada no presente estudo, adotou quatro dimensões, a saber, eficácia de busca, dificuldade de busca, otimismo e responsabilidade/decisão.

As competências de empregabilidade estão associadas à adaptabilidade de carreira, isto é, a capacidade para gerenciar transições de carreira, atuais e futuras (Guzman \& Choi, 2013). Diante dos desafios atuais do mundo do trabalho, como avanço tecnológico, globalização e vínculos empregatícios mais flexíveis, tais habilidades tornam-se ainda mais necessárias (Campos \& Freitas, 2008; Clarke \& Patrickson, 2008). Neste contexto, o papel do Ensino Superior é preparar crítica e reflexivamente os alunos para o mercado, oferecendo oportunidade para desenvolver habilidades de empregabilidade (Campos et al., 2008; Muldoon, 2009).

Nota-se que as dimensões da Escala de Empregabilidade construída por Campos (2010, 2011) caracterizam habilidades que podem ser favorecidas pelo contexto universitário, e assim, podem se associar com os fatores da escala de vivências acadêmicas (QVA-r). O fator Eficácia de busca, uma vez que caracteriza o senso de autoeficácia para conseguir um emprego, depende das experiências de sucesso, feedback positivo e modelos (Bandura, 1977) aos quais o indivíduo vivenciou no período da graduação, tais experiências podem ser identificadas na dimensão Interpessoal do QVA-r, identificada pelo sucesso em procurar ajuda, estabelecer amizades e pelo bom nível de percepção de habilidades sociais. A dimensão Otimismo que contém itens relacio- nados a autoconfiança e sociabilidade pode estar associada ao componente Pessoal que também diz respeito ao autoconceito, e à dimensão Interpessoal que se refere à relação com os amigos, professores e autoridades. O fator Responsabilidade e Decisão indica compromisso e determinação, além da segurança em relação à profissão escolhida, portanto, infere-se alguma associação com os fatores Estudos e Carreira do QVA-r, que refletem organização dos estudos e identidade vocacional, respectivamente. Enfrentamento de Dificuldades ao se referir a características pessoais para superar os desafios da busca e manutenção de um emprego, deveria relacionar-se positivamente com as dimensões Pessoal e Interpessoal da escala de vivências acadêmicas. Com relação à dimensão Institucional da adaptação acadêmica, não há uma hipótese delimitada, uma vez que esta diz respeito à satisfação com a estrutura e recursos da universidade, mas pode ser que o sentimento de amparo institucional reflita principalmente na Eficácia de Busca e Responsabilidade e Decisão.

Embora a associação entre contexto universitário e empregabilidade seja evidente, não foram encontradas pesquisas que relacionassem diretamente medidas destas variáveis. Mas, alguns autores se propuseram a investigar os níveis de empregabilidade dos universitários, o que os estudantes entendem por este termo e como fazem para adquirir tais competências. Por exemplo, Rueda, Martins e Campos (2004) constataram, em uma amostra de 254 estudantes universitários do último ano dos cursos de Psicologia, Administração e Engenharia Civil, que os estudantes conseguem identificar quais são as competências e habilidades associadas ao termo empregabilidades, quando lhes foram apresentados uma lista com 12 itens relacionados ao trabalho. Verificaram, também, que embora com frequências diferentes, esses alunos buscam estratégias semelhantes para conseguirem ingressar na profissão escolhida. Atualização constante e busca de desenvolvimento, ser comunicativo e habilidades para trabalhar em equipe foram as ações de mais destaque. Os alunos do curso de Engenharia demonstram maior preocupação com o 
aproveitamento das oportunidades acadêmicas, enquanto as atitudes relacionadas ao aspecto moral (ser crítico, ético, dedicado, esforçado e respeitoso) foram priorizadas tanto por alunos de Administração quanto pelos de Engenharia.

Zulauf (2006) verificou, também, quais as competências de empregabilidade mais citadas por 60 estudantes de políticas sociais, obtendo como respostas de mais destaque o trabalho em equipe, a autoconfiança, a definição de metas e gerenciamento de tempo e a capacidade de tomada de decisão. Os estudantes também ressaltaram que gostariam de desenvolver tais habilidades a partir das disciplinas curriculares e do ensino de práticas a serem utilizadas no ambiente de trabalho por meio de estágios e estudos de caso.

Em um estudo mais amplo, Campos (2011) aplicou a Escala de Empregabilidade a uma amostra de 628 universitários, e identificou que os alunos de Administração tiveram níveis mais elevados de empregabilidade que os alunos de Engenharia e de Psicologia, sendo que o último obteve o menor escore. De acordo com a autora, pode ser que ocorram diferenças entre os cursos no que se refere ao nível de preparação para o mercado de trabalho.

Diante do exposto, é notável a preocupação dos pesquisadores com o nível de empregabilidade dos estudantes universitários. Entretanto, apenas investigar o nível de competências ou a compreensão do conceito pelos estudantes não é suficiente. É preciso verificar se o aluno está conseguindo extrair de suas vivências acadêmicas recursos para habilitar-se à transição para o mercado de trabalho e sua manutenção nele (Silva, 2010).

Portanto, o objetivo do presente estudo foi explorar as possíveis associações entre vivências acadêmicas e empregabilidade em universitários do último ano de graduação. As expectativas foram de que houvesse uma associação significativa entre as dimensões das escalas, de acordo com as explanações feitas anteriormente, ao longo desta introdução. Com fins exploratórios, averiguaram-se também as possíveis diferenças entre os cursos no que se refere às principais va- riáveis. Baseando-se nas pesquisas encontradas, esperava-se maior nível de empregabilidade entre os alunos de Administração (Campos, 2011; Rueda et al., 2004).

\section{Método}

\section{Participantes}

A amostra foi selecionada por conveniência, segundo a adesão dos coordenadores de curso. Assim, participaram do estudo 60 estudantes universitários do último ano de uma universidade particular do interior paulista, divididos igualmente entre os cursos de Administração (50\%) e Psicologia (50\%). Verificou-se que $76,6 \%(n=46)$ dos participantes eram do sexo feminino, sendo ambos os cursos predominantemente compostos por mulheres (Psicologia $n=27,90,0 \%$; Administração $-n=19 ; 63,3 \%$ ). A idade média foi de 26,7 anos $(D P=5,0)$, variando entre 21 e 39 anos. Entre os alunos de Administração, $1,7 \%$ da amostra estava no $7^{\circ}$ semestre e $48,3 \%$ no $8^{\circ}$ ( $4^{\circ}$ ano), enquanto no curso de Psicologia, $43,3 \%$ cursavam o $9^{\circ}$ semestre e $6,7 \%$, o $10^{\circ}$ semestre ( $5^{\circ}$ ano).

\section{Instrumentos}

Para atingir os objetivos do presente estudo, foram utilizados dois instrumentos de autorrelato, o Questionário de Vivências Acadêmicas Reduzido (QVA-r; Almeida et al., 2002) e a Escala de Empregabilidade (Campos, 2010). Uma breve apresentação dessas medidas é feita a seguir.

O Questionário de Vivências Acadêmicas Versão reduzida (QVA-r; Almeida et al., 2002) possui evidências de validade com amostras de estudantes portugueses. Villar (2003) realizou adaptações linguísticas para sua aplicação no Brasil e outros estudos que indicaram evidências de validade e precisão para o instrumento foram apresentados por Granado (2004).

O QVA-r - versão brasileira (Granado, 2004) tem formato tipo Likert de cinco pontos, com opção de resposta variando de Nada a ver comigo (1) a Tudo a ver comigo (5). É com- 
posto por 55 itens, divididos nas cinco dimensões, a saber: Carreira (12 itens; eg., Acredito que posso concretizar meus valores na profissão que escolhi), Pessoal (14 itens; eg., Sinto-me em forma e com um bom ritmo de trabalho), Interpessoal (12 itens; eg., Faço amigos com facilidade na minha Universidade/Faculdade), Estudo (9 itens; eg., Administro bem meu tempo) e Institucional ( 8 itens; eg., Mesmo que pudesse não mudaria de Universidade/Faculdade).

A dimensão Carreira diz respeito à segurança na escolha da profissão e à percepção de envolvimento e competência pessoal para o curso. $\mathrm{O}$ fator Pessoal envolve o bem-estar físico e psicológico, a estabilidade afetiva, a tomada de decisões, a autonomia e o autoconceito. A dimensão Interpessoal abrange a relação com os colegas, estabelecimento de amizades, procura de ajuda, e percepção de habilidades sociais. O fator Estudo envolve as competências, hábitos de estudo e gestão do tempo e estratégias de aprendizagem. Por fim, a dimensão Institucional compreende a intenção de permanecer ou não na instituição, conhecimento dos serviços e avaliação da infraestrutura (Almeida et al., 2002; Granado, 2004; Schleich, 2006).

A Escala de Empregabilidade (Campos, 2010) é composta por 57 itens dispostos em uma escala de formato tipo Likert de quatro (4) pontos, cujos descritores são: seguramente sim, creio que sim, creio que não e seguramente não. Os itens são dispostos em 4 fatores denominados: Eficácia de Busca (22 itens; eg., Sei utilizar técnicas de busca de emprego adequadamente), Enfrentamento de Dificuldade(10 itens; eg., Não me sinto impulsionado a conseguir êxito), Otimismo (16 itens; eg., Sou uma pessoa alegre e animada) e Responsabilidade e Decisão (9 itens; eg., Trabalho muito para conseguir minhas metas).

O fator Eficácia de Busca está voltado a ações que podem ser consideradas como preparatórias para a busca de emprego, e a noção de que haverá êxito na tarefa. Enfrentamento de Dificuldades envolve habilidades para enfrentar as dificuldades na busca de colocação profissional, abrangendo variáveis psicológicas como responsabilidade, extroversão e autoestima. O fator Otimismo envolve a aceitação de si mesmo e a exposição ao grupo por meio da fala e dos aspectos ligados à liderança e ao otimismo. A dimensão Responsabilidade/Decisão abrange responsabilidade e eleição do curso, sendo Responsabilidade ligada a obstinação e pontualidade, e Decisão relacionado ao autoconhecimento na escolha de carreira.

A Escala de Empregabilidade é aprovada pelo Sistema de Avaliação de Testes Psicológicos - SATEPSI. Informações sobre sua qualidade psicométrica podem ser encontradas no manual do teste (Campos, 2010) e nos estudos realizados por Campos (2011) e Campos e Freitas (2008).

\section{Procedimento}

Após a aprovação do Comitê de Ética em Pesquisa (CAAE: 04411412.7.0000.5514) foram agendados, junto aos coordenadores dos cursos, os dias para aplicação dos instrumentos. Os estudantes que aceitaram participar da pesquisa assinaram o Termo de Consentimento Livre e Esclarecido. A aplicação dos instrumentos foi realizada de forma coletiva em sala de aula e com tempo médio de 40 minutos. Primeiramente foi aplicada a Escala de Empregabilidade e depois o QVA-r.

Para a análise dos dados foram utilizadas estatísticas descritivas, quais sejam, média e desvio-padrão, e provas inferenciais, mais especificamente o Teste $t$ de Student e a correlação de Pearson. Adotou-se nível de significância de $5 \%$ e para a análise dos índices de correlações foi utilizada a classificação de Duffy, McLean e Monshipouri (2011).

\section{Resultados}

A seguir são apresentados os resultados obtidos pela amostra nos instrumentos QVA-r e Escala de Empregabilidade. Como os fatores foram calculados pela média dos itens, a variação possível para o QVA-r foi de 1 a 5 e para a Escala de Empregabilidade foi de 1 a 4 . Na Tabela 1 apresentam-se as estatísticas descritivas. 
Tabela 1

Estatísticas Descritivas dos Instrumentos QVA-r e Escala de Empregabilidade

\begin{tabular}{lcccc}
\hline QVA-r & Mínimo & Máximo & Média & $D P$ \\
\hline Carreira & 2,00 & 5,00 & 3,89 & 0,75 \\
Pessoal & 1,42 & 4,83 & 3,64 & 0,78 \\
Interpessoal & 1,67 & 5,00 & 3,68 & 0,74 \\
Estudo & 1,67 & 4,89 & 3,52 & 0,82 \\
Institucional & 1,63 & 4,75 & 3,47 & 0,71 \\
Escala de Empregabilidade & Mínimo & Máximo & Média & $D P$ \\
Eficácia de Busca & 1,14 & 3,27 & 1,80 & 0,37 \\
Enfrentamento de Dificuldades & 1,70 & 3,80 & 2,93 & 0,46 \\
Otimismo & 1,00 & 2,56 & 1,74 & 0,39 \\
Responsabilidade /Decisão & 1,00 & 2,67 & 1,59 & 0,42 \\
\hline
\end{tabular}

Observa-se que os estudantes pontuaram em todas as dimensões acima do escore médio da escala (3), demonstrando bom nível de adaptação ao contexto universitário. A dimensão Carreira do QVA-r alcançou a maior média, enquanto a dimensão Institucional obteve menor escore. Possivelmente, os participantes deste estudo estão envolvidos com seu projeto de carreira e satisfeitos com o curso, porém não possuem forte vínculo com a instituição.

Em relação à Escala de Empregabilidade, verificou-se um escore médio próximo a dois, denotando nível mediano nas competências de empregabilidade, com destaque do fator Enfrentamento de Dificuldades que atingiu a maior média (2,93). A dimensão Responsabilidade/Decisão obteve a menor. Assim, é possível inferir que os respondentes possuem atitudes e sentimentos positivos em relação à busca de um emprego, entretanto ainda podem ter dúvidas quanto à escolha profissional ou pouca determinação para atingir suas metas. Na Tabela 2 são apresentadas as correlações encontradas entre as dimensões do QVA-re os fatores da Escala de Empregabilidade.

\section{Tabela 2}

Correlação entre as Dimensões do QVA-r e da Escala de Empregabilidade

\begin{tabular}{llcccc}
\hline \multirow{2}{*}{ Carreira } & & $\begin{array}{c}\text { Eficácia } \\
\text { de Busca }\end{array}$ & $\begin{array}{c}\text { Enfrentamento } \\
\text { de dificuldades }\end{array}$ & Otimismo & $\begin{array}{c}\text { Responsabilidade } \\
\text { e decisão }\end{array}$ \\
\hline \multirow{2}{*}{ Pessoal } & $r$ & $0,27^{*}$ & $-0,20$ & $0,35^{* *}$ & $0,31^{*}$ \\
& $p$ & 0,04 & 0,12 & 0,01 & 0,02 \\
Interpessoal & $r$ & 0,23 & $-0,22$ & $0,34^{* *}$ & 0,17 \\
& $p$ & 0,07 & 0,10 & 0,01 & 0,21 \\
Estudo & $r$ & $0,42^{* *}$ & $-0,33^{* *}$ & $0,55^{* *}$ & $0,29^{*}$ \\
& $p$ & 0,01 & 0,01 & 0,01 & 0,02 \\
Institucional & $r$ & 0,21 & $-0,13$ & $0,34^{* *}$ & $0,33^{*}$ \\
& $p$ & 0,11 & 0,33 & 0,01 & 0,01 \\
& $r$ & 0,18 & $-0,20$ & $0,29^{*}$ & $0,28^{*}$ \\
\hline
\end{tabular}

${ }^{*} p<0,05 ;{ }^{* *} p<0,01$ 
Dentre as 20 correlações efetuadas, 12 foram estatisticamente significativas. A dimensão Carreira do QVA-r se correlacionou positivamente com três fatores da Escala de Empregabilidade, sendo que com Eficácia de Busca a magnitude foi fraca, e Otimismo e Responsabilidade/ Decisão com magnitude moderada. Estes dois últimos fatores associam-se teoricamente com a dimensão Carreira que envolve a segurança na escolha do curso e perspectiva na carreira, enquanto as dimensões de empregabilidade representam aceitação e atitude positiva sobre si mesmo, bem como a motivação para a realização e confiança na escolha da carreira.

Quanto à correlação entre o fator Eficácia de Busca e a dimensão Carreira, toda a descrição acima é relevante, pois os itens que compõe esta dimensão de empregabilidade estão voltados para a percepção de capacidade para realizar tarefas para a busca e conquista profissional, bem como para as ações necessárias. A correlação encontrada indica que os indivíduos com elevado índice de autoeficácia de busca podem se sentir mais preparados para procurar um emprego, uma vez que possuem informações sobre os comportamentos que facilitam a colocação profissional na carreira escolhida.

A dimensão Pessoal correlacionou-se positivamente e com magnitude moderada com o fator Otimismo. Tal resultado é compreensível, pois a dimensão Pessoal do QVA-r está relacionada ao bem-estar físico e psicológico, equilíbrio emocional, estabilidade afetiva, autoconfiança, incluindo também o otimismo. Assim, relaciona-se teoricamente com o fator Otimismo da escala de empregabilidade, que diz respeito à aceitação de si mesmo, autoexposição e liderança.

A dimensão Interpessoal do QVA-r correlacionou-se com todos os fatores da Escala de Empregabilidade. Com o fator Enfrentamento de Dificuldades houve associação negativa e moderada, o que não era esperado. Ressalta-se que esse fator possui escores reversos, portanto quanto maior a pontuação, menos dificuldade o indivíduo sente para buscar um emprego e quanto menor a pontuação, mais dificuldade. $\mathrm{O}$ sentido negativo da correlação indica que quando o escore em Enfrentamento de Dificuldades da
Escala de Empregabilidade é baixo, a pontuação na dimensão Interpessoal do QVA-r é alta. Esse resultado é curioso, pois denota que estudantes com maior adaptação acadêmica na dimensão Interpessoal, que dentre outros itens, engloba as relações com colegas e procura de ajuda, percebem-se com menor capacidade para enfrentar os desafios existentes na busca de um emprego.

Quando associada aos fatores Eficácia de Busca e Otimismo, a dimensão Interpessoal apresentou correlação positiva e forte. Então, verifica-se que pessoas com mais relações interpessoais apresentam maior eficácia na busca de emprego e otimismo, ao mesmo tempo em que estabelecem e fazem contatos para a conquista de um emprego, com valores positivos sobre si e autoestima. Já Responsabilidade e Decisão obteve uma correlação fraca com a dimensão Interpessoal do QVA-r. Isso faz sentido, pois, ainda que a relação entre as dimensões seja positiva, não necessariamente estudantes que tenham níveis satisfatórios de habilidades interpessoais, estarão completamente seguros quanto às suas obrigações e comprometidos com a carreira escolhida e vice-versa.

As dimensões Estudo e Institucional do QVA-r correlacionaram-se de forma positiva e respectivamente moderada e fracamente com os fatores Otimismo e Responsabilidade/Decisão. Neste sentido, quanto maior a motivação e comprometimento com a carreira escolhida, no sentido de ter hábitos de estudos e dedicação de tempo, além de adaptação e vínculo com a instituição frequentada, maior o autoconhecimento, responsabilidade com seus compromissos, e assim autoconfiança e expectativa de bons resultados na carreira.

Ao submeter as médias ao teste $t$ de Student, verificou-se que não houve diferenças estatisticamente significativas entre os cursos de graduação investigados. Os estudantes de Administração e de Psicologia apresentam padrões semelhantes de adaptação acadêmica (Pessoal: $t=-0,738, p=0,464$; Carreira: $t=0,426$, $p=0,672$; Interpessoal: $t=0,304, p=0,764$; Estudo: $t=-0,900, p=0,372$; Institucional: $t=-0,751$, $p=0,455)$ e níveis de empregabilidade equivalentes (Eficácia de busca: $t=-0,655, p=0,515$; En- 
frentamento de dificuldades $t=-0,411, p=0,683$; Otimismo: $t=1,178, p=0,244$; Responsabilidade/ Decisão $t=1,682, p=0,098$ ).

\section{Discussão}

O presente estudo teve como objetivo investigar as associações entre vivências acadêmicas e o nível de empregabilidade de alunos universitários em final de curso, além de averiguar se existem diferenças nessas variáveis entre os concluintes de Psicologia e de Administração. Assim sendo, a seguir são discutidos os resultados obtidos.

Quanto às vivências acadêmicas, os participantes do presente estudo tendem a ter experiências mais proeminentes nas dimensões Carreira e, em seguida, na Interpessoal. Estas dimensões estão relacionadas à escolha e às expectativas de carreira, bem como à busca de ajuda e relacionamentos com colegas e amigos. Em outros estudos, a dimensão Carreira foi também a que obteve maior pontuação (Igue et al., 2008; Noronha et al., 2009; Teixeira et al., 2007). As percepções positivas relacionadas à profissão são adequadas ao momento do curso, como apontam Teixeira, Castro, et al. (2007), quanto mais o estudante se aproxima do fim do curso, a tendência é de que a identificação e o compromisso aumente. Quanto à dimensão Interpessoal, esta também se sobressaiu em outros trabalhos que investigaram os cursos de Administração ou de Psicologia (Igue et al., 2008; Noronha et al., 2009; Schleich, 2006), a facilidade para lidar com pessoas parece ser uma característica dos indivíduos que escolhem profissões dessas áreas, ao mesmo tempo, tais profissões requerem essa habilidade (Holland, 1997).

A dimensão Institucional do QVA-r foi a que recebeu a menor média dentre dimensões, revelando níveis mais baixos de adaptação à instituição. Resultados semelhantes foram obtidos por Igue et al. (2008), Noronha et al.(2009) e Schleich (2006). A partir dessa observação, pode-se pensar que os gestores educacionais devem ficar atentos, pois a integração à instituição e o conhecimento de seus serviços podem favorecer o desenvolvimento profissional dos estudantes, bem como a entrada de novos alunos por meio da divulgação feita pelos egressos. Contudo, deve-se considerar também que, os resultados específicos deste estudo, de caráter exploratório, devem ser contextualizados em razão do fato de que a instituição a que os participantes estavam vinculados é particular e os mesmos, estudantes do período noturno. Há uma característica em comum referente ao fato de que, em sua maioria, são trabalhadores ao longo do dia e apenas frequentam a instituição nos períodos de aula, não desfrutando de atividades extracurriculares, acadêmicas ou culturais, que a instituição oferece.

Os resultados descritivos da Escala de Empregabilidade demonstram que os estudantes se sentem capazes de enfrentar os obstáculos frente às tarefas necessárias para conquistar um emprego, bem como possuem senso de autoeficácia para a busca de colocação profissional, sentimentos positivos de capacidade na conquista do emprego e na crença de saber utilizar suas habilidades, visto o alto escore nos fatores Enfrentamento de Dificuldades e Eficácia de Busca. Porém, a baixa pontuação em Responsabilidade/Decisão indica flexibilidade em relação aos objetivos profissionais e na forma de conduzir as tarefas de busca, podendo transmitir que são pouco determinados, assim como, detêm menor grau de autoconhecimento em relação à escolha. Essa classificação, nível mais elevado de Enfrentamento e baixo em Responsabilidade/Decisão, pode ser o reflexo da falta de antecipação do futuro (Bandura, 1977) e de baixos níveis de comportamento exploratório vocacional (Teixeira, Bardagi, \& Hutz, 2007). $\mathrm{O}$ primeiro termo se refere à expectativa do que pode acontecer no futuro a partir do comportamento emitido em momento anterior, o segundo diz respeito à busca de autoconhecimento e informações profissionais. Sugere-se que pesquisas futuras investiguem a relação dessas variáveis vocacionais com a empregabilidade.

$\mathrm{O}$ grande número de correlações encontradas entre os fatores dos instrumentos confirma que existe significativa associação entre as experiências vivenciadas na universidade e as competências de empregabilidade. Como mencionado por outros autores, a adaptação ao curso (Muldoon, 2009) e à carreira (Guzman \& Choi, 
2013) podem contribuir para a aquisição dessas habilidades. A partir dos resultados de estudos anteriores, é possível perceber que os universitários conseguem visualizar essa relação, por exemplo, atualização e desenvolvimento, comunicação, trabalho em equipe, melhor aproveitamento de disciplinas e estágios (Muldoon, 2009; Rueda et al., 2004; Zulauf, 2006) foram vivências acadêmicas associadas ao desenvolvimento de empregabilidade.

$\mathrm{Na}$ presente pesquisa, a dimensão Interpessoal do questionário de vivências acadêmicas obteve correlação significativa com todos os quatro fatores da Escala de Empregabilidade, demonstrando o quanto a habilidade de se relacionar seja com pessoas mais distantes ou amigos está associada às competências de empregabilidade. As vivências no campo do relacionamento interpessoal são favoráveis ao otimismo, à percepção de eficácia de busca e à segurança quanto aos conhecimentos relacionados à profissão, corroborando as hipóteses estipuladas.

A relação negativa entre a adaptação acadêmica na dimensão Interpessoal e o fator Enfretamento de Dificuldades na busca de emprego surpreende, pois se esperava que quanto maior o nível de habilidades sociais e relacionamentos interpessoais, maior seria a percepção de recursos pessoais e/ou características de personalidade que favorecem a busca pela inserção profissional. Provavelmente, mesmo que o formando tenha uma boa adaptação em seu meio social, os momentos próximos à conclusão do curso, bem como a expectativa e a ansiedade pela conquista do emprego, podem gerar alguma insegurança que limite sua percepção dos recursos pessoais (eg., autoestima e extroversão) para alcançar um emprego.

A dimensão Carreira que se refere ao investimento no curso e às expectativas profissionais (Almeida et al., 2002) obteve correlação com três fatores da Escala de Empregabilidade. Ela esteve associada ao Otimismo, Eficácia de Busca e Responsabilidade/Decisão. Seguindo as hipóteses deste estudo, o resultado denota que estar adaptado ao curso, ter segurança da escolha efetuada e se identificar com a profissão, pode contribuir para que a pessoa se torne empregável.

Hábitos de estudos adequados e integração à instituição de ensino também estão ligados às percepções positivas e à determinação e segurança em relação à profissão e às metas, isso foi verificado pela correlação das dimensões Estudo e Institucional com dois fatores de empregabilidade, ambas com Otimismo e Responsabilidade/ Decisão. Por fim, a dimensão Pessoal se correlacionou com Otimismo, afirmando a aproximação entre essas dimensões, uma vez que o domínio Pessoal do questionário de vivências acadêmicas diz respeito ao self e ao bem-estar físico (Almeida et al., 2002), e o fator Otimismo da escala que avalia empregabilidade envolve percepção positiva de si mesmo e a exposição ao grupo por meio da fala (Campos, 2010).

Em síntese, as correlações entre os instrumentos QVA-r e Escala de Empregabilidade indicam o mesmo sentido de estudos anteriores (Campos et al., 2008; Muldoon, 2009; Rosenberg et al., 2012; Rueda et al., 2004; Zulauf, 2006), embora estes não tenham efetuado uma investigação direta com instrumentos específicos, afirmam que as vivências acadêmicas estão relacionadas com a capacidade para conseguir e manter um emprego. Neste estudo, verificou-se que os domínios social (Interpessoal) e vocacional (Carreira) da adaptação acadêmica são aqueles que mais se associam às características de empregabilidade. Isso demonstra que dentre as experiências vividas na universidade, além do conhecimento técnico-científico do curso/profissão, o relacionamento com colegas e professores e atividades extracurriculares também são importantes para a conquista profissional (Rosenberg et al., 2012).

Distintamente de outros estudos (Campos, 2011; Noronha et al., 2009), neste não foram encontradas diferenças estatisticamente significativas entre os cursos nas dimensões de ambas as variáveis investigadas. Neste caso, não foi possível inferir preparação diferenciada entre os cursos para o mercado de trabalho como propôs Campos (2011), contudo a amostra do presente estudo não foi tão diversificada quanto a utilizada na pesquisa da referida autora. Diante disso, o 
questionamento que surge quanto às diferenças ou semelhanças entre os cursos para a empregabilidade, é se seria uma questão exclusivamente do curso, das especificidades de cada instituição ou se as características da empregabilidade são realmente diferentes entre as profissões.

Quanto às limitações da pesquisa, aponta-se a amostra reduzida. $\mathrm{O}$ fato de os participantes serem de apenas uma instituição de ensino particular do interior paulista e somente de dois cursos reforça o caráter meramente exploratório do trabalho. Por exemplo, a equidade quanto aos níveis de adaptação acadêmica e empregabilidade entre os cursos pode ser uma característica restrita a instituição participante. Também, a falta de investigações que analisaram os construtos alvo de forma direta e objetiva e de um modelo teórico delimitado acerca do desenvolvimento das competências de empregabilidade limita a extensão da discussão dos resultados obtidos.

Observando as restrições e os achados do estudo abrem-se possibilidades para futuras pesquisas que possam explorar mais o tema e obter maior compreensão sobre as associações encontradas, inclusive sobre a relação entre enfrentamento de dificuldades na busca de um emprego e vivências acadêmicas no domínio interpessoal. Futuras pesquisas poderiam adotar amostras mais amplas, com cursos e instituições diferentes, bem como um delineamento longitudinal, para confirmar se estudantes com níveis elevados de adaptação acadêmica e de empregabilidade conseguem empregos dentro da área de formação. Também deve ser analisada com maior profundidade a função da universidade na promoção de competências de empregabilidade na ótica dos gestores e dos estudantes.

\section{Referências}

Almeida, L. S., Soares, A. P. C., \& Ferreira, J. A. G. (2000). Transição e adaptação à universidade: Apresentação de um Questionário de Vivências Acadêmicas. Psicologia, 16(2), 189-208.

Almeida, L. S., Soares, A. P. C., \& Ferreira, J. A. G. (2002). Questionário de Vivências Acadêmicas (QVA-r): Avaliação do ajustamento dos estudantes universitários. Avaliação Psicológica, 1(2), 81-93.
Bandura, A. (1977). Self-efficacy: Toward a unifying theory of behavioral change. Psychological Review, 84(2), 191-215.

Campos, K. C. L. (2010). Escala de Empregabilidade: Manual técnico. São Paulo, SP: Vetor.

Campos, K. C. L. (2011). Construção de uma Escala de Empregabilidade: Definições e variáveis psicológicas. Estudos de Psicologia (Campinas), 28(1), 45-55.

Campos, K. C. L., \& Freitas, F. A. (2008). Empregabilidade: Construção de uma escala. Psico-USF, 13(2), 189-201.

Campos, K. L., Vieira, V. F., Camargo, A. P., Scheguschevski, A., Tavares, F. P., Piovezan, N. M., \& Alkschbirs, S. R. (2008). Empregabilidade e competências: Uma análise de universitários sob a ótica de gestores de recursos humanos. Revista Psicologia: Organização e Trabalho, 8(2), 159183.

Clarke, M., \& Patrickson, M. (2008). The new covenant of employability. Employee Relations, 30(2), 121-141.

Duffy, S. P., McLean, S. L., \& Monshipouri, M. (2011). Pearson's $r$ correlation. Retrieved February 20, 2011, from http://faculty.quinnipiac. edu/ libarts/polsci/Statistics.html

Granado, J. I. F. (2004). Vivência acadêmica de universitários brasileiros: Estudo de validade e precisão do QVA-r (Dissertação de mestrado, Universidade São Francisco, Itatiba, SP, Brasil).

Guzman, A. B., \& Choi, K. O. (2013). The relations of employability skills to career adaptability among technical school students. Journal of Vocational Behavior, 82, 199-207.

Holland, J. L. (1997). Making vocational choices: A theory of vocational personalities and work environments ( $3^{\text {rd }}$ ed.). Odessa, FL: Psychological Assessment Resources.

Igue, E. A., Bariani, I. C. D., \& Milanesi, P. V. B. (2008). Vivência acadêmica e expectativas de universitários ingressantes e concluintes. PsicoUSF, 13(2), 155-164.

Lemos, T. H. (2010). Escala de Avaliação da Vivência Acadêmica: Estudo de validade com universitários da Paraíba (Dissertação de mestrado, Programa de Pós-Graduação em Psicologia, Universidade São Francisco, Itatiba, SP, Brasil).

Muldoon, R. (2009). Recognizing the enhancement of graduate attributes and employability through 
part-time work while at university. Active Learning in Higher Education, 10(3), 237-252.

Noronha, A. P. P., Martins, D. F., Gurgel, M. G. A., \& Ambiel, R. A. M. (2009). Estudo correlacional entre interesses profissionais e vivências acadêmicas no ensino superior. Psicologia Escolar e Educacional, 13(1), 143-154.

Rosenberg, S., Heimler, R., \& Morote, E.-S. (2012). Basic employability skills: A triangular design approach. Education \& Training, 54(1), 7-20.

Rueda, F. J. M., Martins, L. J., \& Campos, K. C. L. (2004). Empregabilidade: O que os alunos universitários entendem sobre isto? Psicologia: Teoria e Prática, 6(2), 63-73.

Schleich, A. L. R. (2006). Integração na educação superior e satisfação acadêmica de estudantes ingressantes e concluintes: Um estudo sobre relações (Dissertação de mestrado, Faculdade de Educação, Universidade Estadual de Campinas, SP, Brasil).

Silva, C. S. C. (2010). De estudante a profissional - A transição de papéis na passagem da universidade ao mercado de trabalho (Dissertação de mestrado, Programa de Pós-Graduação em Psicologia, Universidade Federal do Rio Grande do Sul, Porto Alegre, RS, Brasil).
Soares, A. B., Baldez, M. O., \& Mello, T. V. (2011). Vivências acadêmicas em estudantes universitários do Estado do Rio de Janeiro. Interação em Psicologia, 15(1), 59-69.

Teixeira, M. A. P., Bardagi, M. P., \& Hutz, C. S. (2007). Escalas de Exploração Vocacional (EEV) para universitários. Psicologia em Estudo (Maringá), 12, 195-202.

Teixeira, M. A. P., Castro, G. D., \& Piccolo, L. R. (2007). Adaptação à universidade em estudantes universitários: Um estudo correlacional. Integração em Psicologia, 11, 211-220.

Zulauf, M. (2006). Ensino superior e desenvolvimento de habilidades para a empregabilidade: Explorando a visão dos estudantes. Sociologias, $8(16), 126-155$.
Recebido: 08/08/2013

$1^{a}$ revisão: $27 / 11 / 2013$ Aceite final: 08/12/2013 